\title{
Mitochondrial dysfunction in mouse models of Parkinson's disease revealed by transcriptomics and proteomics
}

\author{
Desmond J. Smith
}

Published online: 5 December 2009

(C) The Author(s) 2009. This article is published with open access at Springerlink.com

\begin{abstract}
It has been long thought that neuronal loss in Parkinson's disease (PD) is related to reactive oxygen species from mitochondrial dysfunction. However, there have been few investigations surveying both transcriptome and proteome in PD. This review focuses on recent work using microarrays and mass spectrometry to examine neurotoxicological models of PD in the mouse. Molecular pathways involved in oxidative phosphorylation, oxidative stress, apoptosis/cell death, signal transduction and neurotransmission were highlighted. Analysis of tyrosine nitration suggested that this important post-translational modification, due to conjugation of reactive oxygen species with nitric oxide, may play an important role in signal transduction as well as the molecular pathology of PD. Thus, the combined investigations highlight known pathways in PD but also point to new directions for research, implicating particularly the role of relatively understudied classes of post-translational modifications in normal cell signaling and neurological disorders.
\end{abstract}

Keywords Parkinson's disease · Mitochondrion ·

Oxidative stress $\cdot$ Methamphetamine $\cdot$ MPTP

\section{Oxidative stress and Parkinson's disease}

Parkinson's disease (PD) is the second most common cause of neurological disability after Alzheimer's disease (Tsang and Chung 2009; Zhou et al. 2008). The disorder is charac-

\section{J. Smith $(\bowtie)$}

Department of Molecular and Medical Pharmacology,

David Geffen School of Medicine, UCLA,

CHS 23-120, Box 951735, Los Angeles, CA 90095-1735, USA

e-mail: DSmith@mednet.ucla.edu terized by the tetrad of tremor, rigidity, bradykinesia and postural instability, while the hallmark pathology is loss of dopaminergic neurons in the nigrostriatal pathway. The overwhelming majority of $\mathrm{PD}$ cases are sporadic, though rare monogenic forms are known. Affected neurons frequently contain eosinophilic inclusion bodies called Lewy bodies. However, the mechanisms initiating neuronal pathology in sporadic PD are largely obscure.

Studies of both humans and mouse models have implicated a complex cascade of oxidative damage in PD (Lin and Beal 2006). A principal source of this oxidative chain is the mitochondrion, the main generator of superoxide radicals $\left(\cdot \mathrm{O}_{2}{ }^{-}\right)$. These radicals are produced as a byproduct of the electron transport chain employed in oxidative phosphorylation. Complex I of the electron transport chain is responsible for most of the burden. An intricate array of mechanisms exists to efficiently mop up superoxide and other reactive oxygen species (ROS). Superoxide dismutase (SOD) converts $\cdot \mathrm{O}_{2}{ }^{-}$to hydrogen peroxide $\left(\mathrm{H}_{2} \mathrm{O}_{2}\right)$, which is subsequently converted into water and oxygen in a reaction catalyzed by catalase and peroxiredoxin. However, in Fenton's reaction $\mathrm{Fe}^{2+}$ can catalyze the transformation of $\mathrm{H}_{2} \mathrm{O}_{2}$ into the highly damaging hydroxide radical, $\bullet \mathrm{OH}$.

The oxidative stress associated with PD may also play a direct role in the apoptosis of dopaminergic neurons, since many of the components of the apoptotic cascade are redox sensitive (Mattson 2000). Furthermore, mitochondrial dysfunction contributing to oxidative damage in PD may also trigger apoptosis, since this organelle is intimately involved in initiating programmed cell death (Zamzami and Kroemer 2001).

While the role of nitric oxide $(\bullet \mathrm{NO})$ as an essential neurotransmitter is well established, this signaling molecule can also be another source of neuronal oxidative damage through production of reactive nitrogen species (RNS). 
Nitric oxide also mediates chronic inflammation, thus linking inflammatory responses with oxidative injury. Conjugation of $\bullet \mathrm{NO}$ with $\cdot \mathrm{O}_{2}^{-}$gives the reactive peroxynitrite $\left(\mathrm{ONOO}^{-}\right)$, which in turn gives rise to the damaging molecules nitrogen dioxide $\left(\cdot \mathrm{NO}_{2}\right), \cdot \mathrm{OH}$, or the carbonate radical $\cdot \mathrm{CO}_{3}{ }^{-}(10$ 12) (Beckman and Koppenol 1996; Reiter et al. 2000; Tien et al. 1999). Importantly, $\mathrm{ONOO}^{-}$and $\cdot \mathrm{NO}_{2}$ can conjugate with the tyrosine sidechain to form nitrated tyrosine, a modification that can potentially alter protein function and modulate signal transduction (Radi 2004).

\section{Transcriptomic and proteomic studies of mouse models of PD}

Despite the considerable circumstantial data suggesting an important role for oxidative stress in PD, there was little information on the concerted changes occurring in the transcriptome and proteome in this disorder. In a recent paper (Chin et al. 2008) microarrays and mass spectrometry were used to investigate the transcriptome and proteome, respectively, in the striatum of mouse models of PD. The mouse models were created using the neurotoxin 1-methyl4-phenyl-1,2,3,6-tetrahydropyridine (MPTP) (Vijitruth et al. 2006) and toxic doses of methamphetamine (Melega et al. 1997; Sonsalla et al. 1996) (Fig. 1). Using two independent pharmacological models of PD enabled identification of common themes, more likely representing core pathways for $\mathrm{PD}$, while effects restricted to either of the drugs represent idiosyncratic drug reactions. MPTP exerts its toxic effects through enzymatic conversion to the cation 1-methyl-4-phenylpyridinium (MPP+) by monoamine oxidase B (MAOB) (Smeyne and Jackson-Lewis 2005). MPP+ is then specifically carried into dopaminergic neurons by the dopamine transporter (DAT) where it inhibits complex I of the mitochondrial electron transport chain. Inhibition of mitochondrial respiration suffocates the dopaminergic neuron, while further damage is inflicted by the resulting onslaught of ROS.

The transcriptomic analysis employed Affymetrix arrays, while the proteomic analysis used tryptic digestion of

Fig. 1 Structures of MPTP and methamphetamine
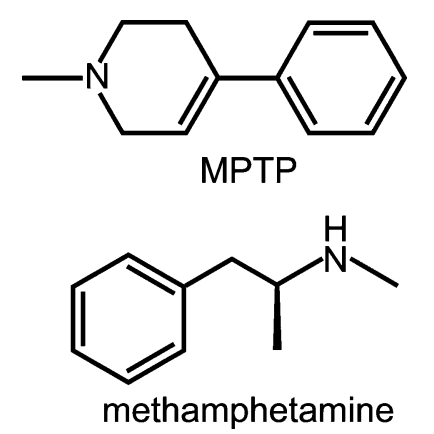

proteins followed by liquid chromatography (LC) combined with a time-of-flight, Fourier transform (FT) ion cyclotron resonance (ICR) mass spectrometer (MS) (LC FTICR MS). The MS instrumentation was operated using the accurate mass and time (AMT) tag approach, in which peptide identification was based not on the more common approach of MS/MS fragmentation patterns, but on directly matching LC-MS features with a pre-established AMT tag database employing accurately measured LC elution time and mass information (Liu et al. 2007; Zimmer et al. 2006). The LC FTICR MS approach delivers high throughput capability to analyze large sample numbers.

Relative peptide quantitation used ${ }^{16} \mathrm{O} /{ }^{18} \mathrm{O}$ ratios in which a universal ${ }^{18} \mathrm{O}$-labeled internal standard was employed for control samples. Trypsin-catalyzed exchange was used for the labeling procedure (Qian et al. 2005). To greatly enhance protein coverage, a cysteinyl-peptide enrichment (CPE) strategy was employed, in which peptides were treated with DTT followed by affinity purification on thiopropyl beads and elution with additional DTT. This quantitative cysteinylpeptide enrichment technology (QCET) is a powerful alternative to the widely-used Isotope-Coded Affinity Tags (ICAT) method. Another benefit of merging ${ }^{16} \mathrm{O} /{ }^{18} \mathrm{O}$ labeling and CPE for proteomic quantitation is that both Cys- and non-Cys-peptides can be evaluated, in contrast to ICAT, where only Cys-peptides are quantitated. The pooled results from the Cys and non-Cys peptides improve quantitation and enhance proteome coverage.

\section{Mitochondrial dysfunction, oxidative stress and apoptosis in PD striatum}

A total of 1624 striatal proteins were quantitated using the LC FTICR MS and AMT strategies, suggesting substantial proteome coverage. Significant abundance changes were found in 149 and 199 proteins as a result of METH and MPTP treatment, respectively $(p<0.05)$. The 215 most strongly significant proteins are depicted in a heat map in Fig. 2. A large percentage of proteins displayed consistent abundance regulation in both the MPTP and METH-treated mice. Consistent with this, relative protein abundance changes in response to both neurotoxins were highly significantly correlated, suggesting a commonality of mechanism. Purkinje cell protein 4 (Pcp4) provided an illustration of quantitation sensitivity, displaying a decrease of $<30 \%$ following MPTP, similar to that reported in the literature (Skold et al. 2006).

The striatal transcriptome of the MPTP and METH treated mice were also analyzed using microarrays. Compared to controls, the MPTP-treated striata showed 34 significantly upregulated and 29 downregulated genes, while the METHtreated striata showed 51 significantly upregulated and 


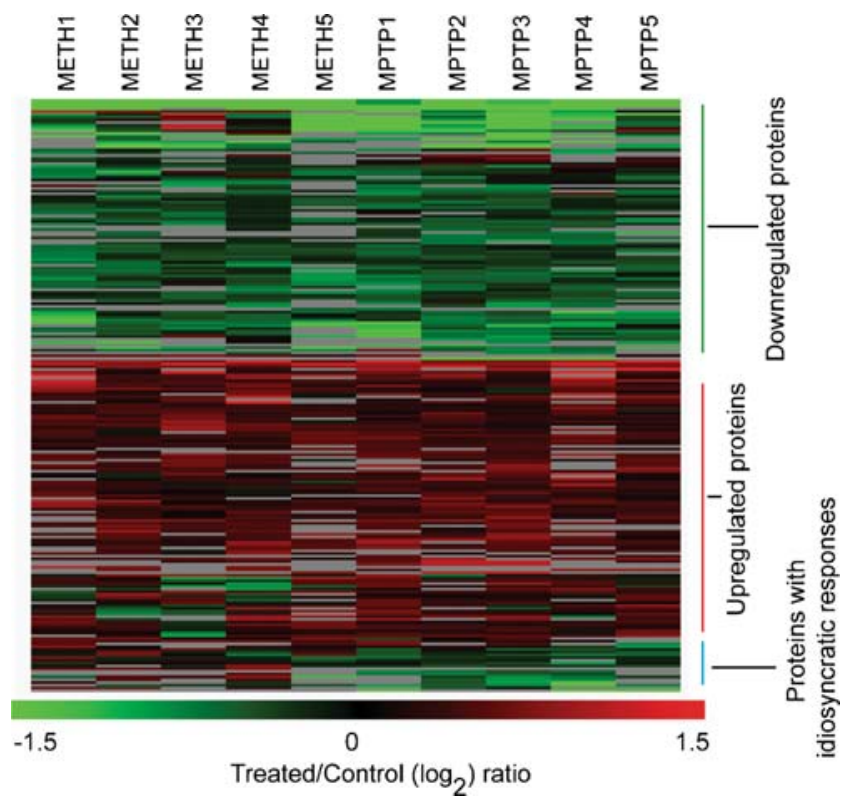

Fig. 2 Alterations in protein abundance of MA and MPTP-treated striata compared to vehicle treated controls. The 215 proteins with significant changes displayed. Columns show relative quantities of individual samples, while rows represent different proteins

40 downregulated. Just as for the proteomics, there was significant overlap between the two disease models with highly significant correlations of relative transcript abundance ratios.

Together, the transcriptomic and proteomic data revealed that the expression of 195 genes was altered in the striatum of the two models of PD, giving a more complete picture of the pathways involved in this disorder. A number of functional categories were prominent, including mitochondrial dysfunction, oxidative phosphorylation, oxidative stress, apoptosis/cell death, signal transduction and neurotransmission. Genes downregulated in mice treated with both neurotoxins included five subunits of complex I and several ATP synthase subunits, consistent with a picture of striatal mitochondrial dysfunction. Complex I deficiency augments soluble mitochondrial reserves of cytochrome $\mathrm{C} 1$ (Perier et al. 2005). Consistently, levels of cytochrome C1, a pro-apoptotic protein, were also elevated in MPTP-treated mice. Furthermore, F-type ATPase complex levels were diminished, concordant with mitochondrial dysfunction and inhibited ATP generation. Also decreased were levels of V-type ATPase, involved in fueling synaptic vesicles with neurotransmitters.

Adding to the landscape of oxidative stress, antioxidant gene products (Gpx4 and Gstm5), and gene products potentially regulated in response to oxidative damage (Dusp1 and Fos) exhibited decreased abundance, while oxidative stress response proteins (PI3K, Usp14 and Rras2) were induced (Goldshmit et al. 2001; Lee et al. 1999).

\section{Surveying endogenously nitrated proteins using proteomics}

Since $\cdot \mathrm{NO}$ can combine with ROS to cause nitration of tyrosine residues, nitrated tyrosines were sought by searching the normal mouse brain AMT database for peptides with tyrosines containing an supplementary mass equivalent to an added $\mathrm{NO}_{2}$ (Sacksteder et al. 2006). A total of 29 unique proteins were found with nitrotyrosine modifications. Approximately $0.4 \%$ of total proteins were nitrated, consistent with the known high in vivo selectivity of tyrosine nitration (Ischiropoulos 2003). Of the nitrotyrosines, 11 of the modifications were on residues known to be targets of tyrosine kinases, suggesting the possibility that the nitration may play a role in normal signal transduction.

The nitrated tyrosines were found on highly abundant proteins, such as tubulin and actin as well as proteins expressed at very low levels, such as receptors and nuclear transcription factors. The identified proteins usually had low nitration levels, with a range of $<1$ to $50 \%$. Consistent with the role of the mitochondrion in providing ROS, there was an $\sim 2-3$-fold proteins. More than half of the identified nitrated proteins had previously been associated with neurodegenerative disorders such as PD or Alzheimer's disease through altered transcript levels, protein abundance or gene mutation. Furthermore, the presence of nitrated proteins in normal brain was confirmed by Western blots of brain proteins using antibodies recognizing nitrotyrosine. Increased levels of nitrated proteins were found in MPTP treated brain, suggesting a role for nitration in PD.

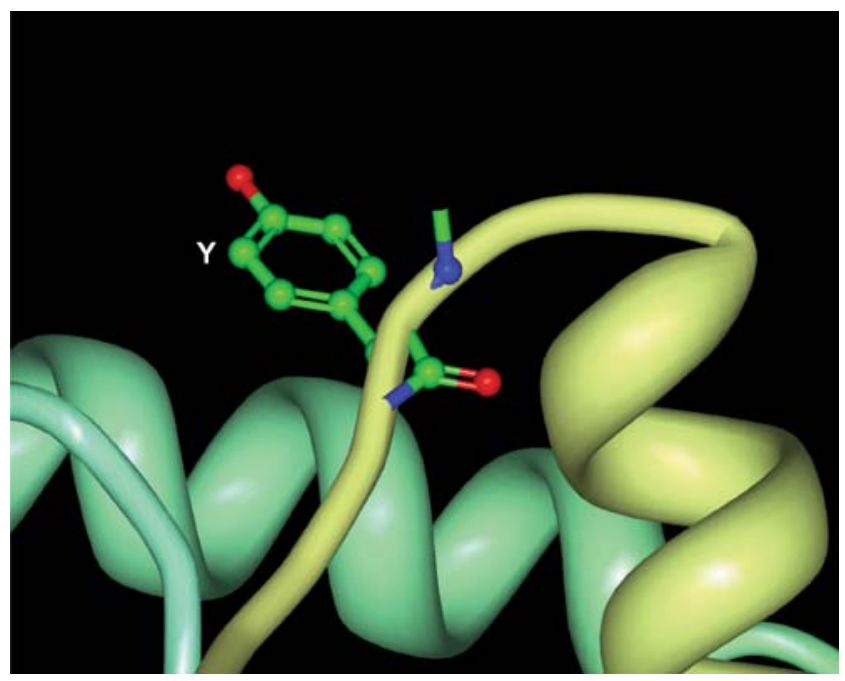

Fig. 3 Tyrosine 269 (Y) of creatine kinase B chain presented on exposed loop. This residue is nitrated in brain. Protein structure downloaded from Protein Data Bank (www.pdb.org, PDB ID: 1QH4) (Berman et al. 2000) and presented using ProteinWorkshop 3.5, part of the Molecular Biology Toolkit (Moreland et al. 2005) 
Scrutiny of the nitrated protein sequences revealed an increased frequency of basic amino acids near nitrated tyrosines, indicating that a positive charge enhances tyrosine nitration. Both methionines and cysteines were found close to nitrotyrosines, opposing the notion that tyrosine nitration is impeded by competition from these residues (Ischiropoulos 1998; Zhang et al. 2005). Furthermore, available and predicted three-dimensional structures from the set of nitrated proteins revealed that nitrated tyrosines showed a strong preference for accessibility and were often on the surface of loops (Fig. 3).

The ER chaperone, glucose-regulated protein 78 (GRP78), and the eukaryotic initiation factor 2 (EIF2), each essential in the unfolded protein response, were both nitrated. Nitration may thus encourage the formation of protein inclusion bodies such as Lewy bodies. Tyrosine hydroxylase $(\mathrm{TH})$ catalyzes the rate-limiting step of dopamine synthesis and diminished dopamine production due to decreased tyrosine hydroxylase activity is an early event in PD. TH is activated by the TH activation protein, a 14-3-3 interaction protein, which binds and stabilizes the active Ser40-phosphorylated form of TH. In contrast, TH inactivation occurs via the phosphatase, PP2a, which is itself activated by binding with $\alpha$-synuclein, a protein mutated in a monogenic form of PD and a component of the Lewy body (Peng et al. 2005). The TH activation protein was nitrated on two tyrosines. The endogenous nitration of the $\mathrm{TH}$ activation protein found using the proteomic approach, together with the known MPTPinduced nitration of both TH and $\alpha$-synuclein, implies a hub of nitration activity potentially illuminating the early dopamine deficits in the inflammatory and oxidative damage models of PD (Przedborski et al. 2001; Uversky et al. 2005; Yamin et al. 2003).

The importance of the nitrated proteins for normal neuronal function combined with the observation that nitration sites are sequence-dependent and often loci for phosphorylation implies that nitrotyrosine modification should be considered as a mechanism for normal cell signaling and also a causal factor in neurodegenerative disease.

\section{Conclusions}

Although tantalizing glimpses of possible mechanistic connections at the nexus of the mitochondrion, oxidative stress and PD have been revealed by current studies, it is clear that our understanding of this complex interplay is only in its infancy. On the other hand, the power of sensitive and high-throughput technologies to view the transcriptome and proteome will continue to improve for the foreseeable future. Phenomena such as alternative splicing, variant transcriptional initiation and termination sites as well as hitherto unimagined secondary protein modifications will eventually reveal the entire pathway of damage in $\mathrm{PD}$, from initial molecular insult to final neurological disorder.

Acknowledgments Supported by NIH R01 NS050148.

Open Access This article is distributed under the terms of the Creative Commons Attribution Noncommercial License which permits any noncommercial use, distribution, and reproduction in any medium, provided the original author(s) and source are credited.

\section{References}

Beckman JS, Koppenol WH (1996) Am J Physiol 271:C1424-C1437 Berman HM, Westbrook J, Feng Z, Gilliland G, Bhat TN, Weissig H, Shindyalov IN, Bourne PE (2000) Nucleic Acids Res 28:235242

Chin MH, Qian WJ, Wang H, Petyuk VA, Bloom JS, Sforza DM, Lacan G, Liu D, Khan AH, Cantor RM, Bigelow DJ, Melega WP, Camp DG 2nd, Smith RD, Smith DJ (2008) J Proteome Res 7:666-677

Goldshmit Y, Erlich S, Pinkas-Kramarski R (2001) J Biol Chem 276:46379-46385

Ischiropoulos H (1998) Arch Biochem Biophys 356:1-11

Ischiropoulos H (2003) Biochem Biophys Res Commun 305:776783

Lee AC, Fenster BE, Ito H, Takeda K, Bae NS, Hirai T, Yu ZX, Ferrans VJ, Howard BH, Finkel T (1999) J Biol Chem 274: 7936-7940

Lin MT, Beal MF (2006) Nature 443:787-795

Liu T, Belov ME, Jaitly N, Qian WJ, Smith RD (2007) Chem Rev 107:3621-3653

Mattson MP (2000) Nat Rev Mol Cell Biol 1:120-129

Melega WP, Raleigh MJ, Stout DB, Lacan G, Huang SC, Phelps ME (1997) Brain Res 766:113-120

Moreland JL, Gramada A, Buzko OV, Zhang Q, Bourne PE (2005) BMC Bioinformatics 6:21

Peng X, Tehranian R, Dietrich P, Stefanis L, Perez RG (2005) J Cell Sci 118:3523-3530

Perier C, Tieu K, Guegan C, Caspersen C, Jackson-Lewis V, Carelli V, Martinuzzi A, Hirano M, Przedborski S, Vila M (2005) Proc Natl Acad Sci USA 102:19126-19131

Przedborski S, Chen Q, Vila M, Giasson BI, Djaldatti R, Vukosavic S, Souza JM, Jackson-Lewis V, Lee VM, Ischiropoulos H (2001) J Neurochem 76:637-640

Qian WJ, Monroe ME, Liu T, Jacobs JM, Anderson GA, Shen Y, Moore RJ, Anderson DJ, Zhang R, Calvano SE, Lowry SF, Xiao W, Moldawer LL, Davis RW, Tompkins RG, Camp DG 2nd, Smith RD (2005) Mol Cell Proteomics 4:700-709

Radi R (2004) Proc Natl Acad Sci USA 101:4003-4008

Reiter CD, Teng RJ, Beckman JS (2000) J Biol Chem 275:3246032466

Sacksteder CA, Qian WJ, Knyushko TV, Wang H, Chin MH, Lacan G, Melega WP, Camp DG 2nd, Smith RD, Smith DJ, Squier TC, Bigelow DJ (2006) Biochemistry 45:8009-8022

Skold K, Svensson M, Nilsson A, Zhang X, Nydahl K, Caprioli RM, Svenningsson P, Andren PE (2006) J Proteome Res 5:262-269

Smeyne RJ, Jackson-Lewis V (2005) Brain Res Mol Brain Res 134:57-66 
Sonsalla PK, Jochnowitz ND, Zeevalk GD, Oostveen JA, Hall ED (1996) Brain Res 738:172-175

Tien M, Berlett BS, Levine RL, Chock PB, Stadtman ER (1999) Proc Natl Acad Sci USA 96:7809-7814

Tsang AH, Chung KK (2009) Biochim Biophys Acta 1792:643650

Uversky VN, Yamin G, Munishkina LA, Karymov MA, Millett IS, Doniach S, Lyubchenko YL, Fink AL (2005) Brain Res Mol Brain Res 134:84-102
Vijitruth R, Liu M, Choi DY, Nguyen XV, Hunter RL, Bing G (2006) J Neuroinflammation 3:6

Yamin G, Uversky VN, Fink AL (2003) FEBS Lett 542:147-152

Zamzami N, Kroemer G (2001) Nat Rev Mol Cell Biol 2:67-71

Zhang H, Xu Y, Joseph J, Kalyanaraman B (2005) J Biol Chem 280:40684-40698

Zhou C, Huang Y, Przedborski S (2008) Ann N Y Acad Sci 1147:93-104

Zimmer JS, Monroe ME, Qian WJ, Smith RD (2006) Mass Spectrom Rev 25:450-482 